\section{Emerging Science Abstracts}

The Emerging Science abstracts were presented at the 2013 AAN Annual Meeting. Abstracts qualify for Emerging Science presentations by having key aspects of research conducted after the October 15th abstract submission deadline and must be new and of sufficient scientific importance to warrant expedited presentation and publication. The Science Committee is committed to presenting the best neuroscientific research at the Annual Meeting; 12 abstracts were accepted for dual presentation and 9 were accepted as poster presentations.

\section{Novel CSF biomarkers for frontotemporal lobar degeneration with lesions immunoreactive to TDP-43 (FTLD-TDP) William $H u, M D, P h D$; Kelly Watts, MS; Murray Grossman,} MD, FAAN; Jonathan Glass; James Lah, MD; John Trojanowski, MD, PhD; Allan Levey, $M D, P h D$

OBJECTIVE: To validate five previously identified CSF biomarkers for FTLD-TDP, and to report a novel, robust, stand-alone CSF biomarker for FTLD-TDP. BACKGROUND: There is currently no reliable way to predict the underlying FTLD pathology while the patients are still living, and an ante-mortem biomarker for one of the main FTLD subtypes (FTLD-TDP or FTLD-Tau) can significantly enhance the pathology-based FTLD diagnosis and clinical trials for FTLD-TDP and FTLD-Tau. DESIGN/METHODS: Two independent cohorts of patients with frontotemporal dementia (FTD) were recruited independently from Emory University (Atlanta, GA) and University of Pennsylvania (Penn; Philadelphia, PA) to undergo CSF analysis. These include patients with high likelihood FTLD-TDP (FTD patients with amyotrophic lateral sclerosis or FTD patients with mutations in PGRN or C9ORF72) and patients with high likelihood FTLD-Tau (FTD patients with progressive supranuclear palsy or FTD patients with mutations in MAPT). Levels of five CSF previously identified proteins were measured, along with levels of total Tau (t-Tau) and Tau phosphorylated at threonine $181\left(\mathrm{p}-\mathrm{Tau}_{181}\right)$. RESULTS: 29 Emory patients and 40 Penn patients participated in the study, including 43 patients with high likelihood FTLD-TDP and 26 patients with high likelihood FTLD-Tau. Using the Emory cohort, we validated the group level differences in CSF eotaxin-3, Fas, and IL-23 ( $p<0.01)$ previously identified using the Penn cohort. We also identified the ratio of $\mathrm{p}-\mathrm{Tau}_{181}$ to $\mathrm{t}-\mathrm{Tau}(\mathrm{p} / \mathrm{t}-\mathrm{Tau}$ ratio) to be significantly lower in Emory FTLD-TDP cases compared to Emory FTLD-Tau and AD cases. Using the Penn cohort as a validation set, $\mathrm{p} / \mathrm{t}-$ Tau ratio alone is sufficient to identify FTLDTDP with $88 \%$ sensitivity and $73 \%$ specificity. CONCLUSIONS: CSF biomarkers have the potential of accurately identifying FTLD-TDP, and further development of this and other FTLD-TDP biomarkers will significantly accelerate the ante-mortem prediction of FTLDTDP pathology and design of substrate-specific FTLD clinical trials.

Study Supported By: N/A

Disclosures: Dr. Hu has nothing to disclose. Ms. Watts has nothing to disclose. Dr. Grossman has received personal compensation for activities with Allon Therapeutics. Dr. Glass received research support from Neuralstem. Dr. Lah has received research support from Elan, Medivation, Merck, and Ceregene. Dr. Trojanowksi has received personal compensation for activities with Pfizer, Johnson \& Johnson, MetLife, and BMS. Dr. Trojanowski has received royalty payments through Penn licenses. Dr. Trojanowksi has received research support from AstraZeneca and BMS. Dr. Levey has received personal compensation for activities with Genomind as an advisory board member. Dr. Levey has received research support from Janssen, Merck, Ceregene, and Medivation.

\section{Safety and efficacy of ORM-12741 on cognitive and behavioral symptoms in patients with Alzheimer's disease: A randomized, double-blind, placebo-controlled, parallel group, multicenter,} proof-of-concept 12 week study Juha Rouru; Keith Wesnes; Jutta Hänninen; Michael Murphy, MD, PhD; Henry Riordan, PhD; Juha Rinne, $M D, P h D, F A A N$

OBJECTIVE: The primary objectives were to evaluate safety, tolerability and efficacy of ORM-12741 as add-on therapy in patients with Alzheimer's disease (AD). BACKGROUND: ORM-12741 is a highly potent and selective alpha-2C adrenoceptor (AR) antagonist that has demonstrated efficacy in rodent models suggesting beneficial effects on cognition and behavioral symptoms in $\mathrm{AD}$, as well as good tolerability across seven phase I studies. This is the first report of a selective alpha-2C AR antagonist in $\mathrm{AD}$ patients. DESIGN/METHODS: This was a phase IIa, randomized, double-blind, placebo-controlled study of 100 moderate $\mathrm{AD}$ patients (MMSE scores 12-21) with behavioral symptoms (Neuropsychiatric Inventory (NPI) score of 215). Patients were allocated to two flexible dose levels of either 30 to $60 \mathrm{mg}$ or 100 to 200 mg of ORM-12741 or matching placebo twice daily for 12 weeks as add-on to their stable cholinesterase inhibitor therapy ( \pm memantine). Efficacy was assessed primarily with computerized tests from CDR System, from which standard composite scores were derived including: Quality of Episodic Memory (QEM), Quality of Working Memory (QWM), Quality of Memory (QM), Speed of Memory and Power of Attention. NPI was assessed to quantify the effects on behavioral and psychological symptoms. RESULTS: Clear and statistically significant positive treatment effects were noted for ORM-12741 on QEM $(\mathrm{p}=0.03)$ and $\mathrm{QM}(\mathrm{p}=0.0127)$ compared to the placebo group over the 12 week treatment period with no clear difference in efficacy between the two active dose groups. In addition, a positive trend was noted for both QWM and NPI total score primarily for the low dose group. No significant differences were identified on the other scores. ORM-12741 was generally well tolerated in the study. CONCLUSIONS: The study yielded significant positive effects of ORM-12741 on episodic memory in moderate $\mathrm{AD}$ patients as add-on therapy over 12 weeks suggesting further study in longer term trials.

Study Supported By: Orion Pharma.

Disclosures: Dr. Rouru has received personal compensation for activities with Orion Pharma. Dr. Wesne has received personal compensation for activities with Bracket as an employee. Dr. Wesnes holds stock and or stock options in Bracket. Dr. Hanninen has received personal compensation for activities with Orion Pharma. Dr. Murphy has received personal compensation for activities with Worldwide Clinical Trials.
Dr. Riordan has nothing to disclose. Dr. Rinne has received research support from Orion Pharma, Pfizer, Bristol-Myers-Squibb, GE, Noscira, Roche and AC-Immune.

\section{CSF $(1,3) b$-D-glucan as an adjunctive test for invasive CNS fungal infection due to presumed Exserohilum}

rostratum Jennifer Lyons, MD; Kiran Thakur, MD; Dorlan Kimbrough, MD; Bryan Smith, MD; Farrah Mateen, MD; Kieren Marr, MD; Sean Zhang, $M D$, PhD; Karen Roos, $M D$, FAAN

OBJECTIVE: To detail experience with $(1,3)$ b-D-glucan (BG) quantification from cerebrospinal fluid (CSF) as an adjunctive diagnostic test for fungal meningitis during the recent U.S. outbreak. BACKGROUND: From May - September 2012, over 14,000 patients who underwent epidural steroid injection were exposed to methylprednisolone acetate from lots contaminated with environmental fungi. Many patients developed serious central nervous system complications, but definitive fungal identification has been elusive. Whereas BG detection in serum can assist in diagnosis of systemic fungal infection, its utility as a CSF assay is unknown. DESIGN/METHODS: BG was quantified via Fungitell ${ }^{\circledR}$ assay at Beacon Diagnostic Laboratories (East Falmouth, MA) from CSF of 6 patients who were exposed to the implicated medication but whose fungal cultures and polymerase chain reactions were negative. 4 fit CDC case definitions for probable meningitis. 2 did not fit criteria but underwent lumbar puncture due to exposure history in the setting of clinical illness. RESULTS: All 4 probable meningitis cases had detectable CSF BG. One of the cases had two samples separated by 2 weeks during which she was treated and showed symptomatic resolution with voriconazole, and the titer decreased from the first to the second test. Both cases not fitting criteria for probable meningitis had undetectable CSF BG, and clinically their presentations were thought to be due to other causes. CONCLUSIONS: Establishing the diagnosis of fungal meningitis in the current nationwide outbreak has been difficult, and little is known about the natural history of this disease or therapeutic responses. Measurement of CSF BG may be a useful adjunctive test for the diagnosis and therapeutic monitoring of fungal meningitis during an outbreak or for culture-negative cases. Additionally, sequential quantification could be useful for determination of therapy duration, but more data would be necessary to understand the anticipated kinetics of antigen positivity and relationship to suspected disease.

Study Supported By: N/A

Disclosures: Dr. Lyons has nothing to disclose. Dr. Thakur has nothing to disclose. Dr. Kimbrough has nothing to disclose. Dr. Smith has nothing to disclose. Dr. Mateen has nothing to disclose. Dr. Marr has received personal compensation for activities with Astellas, Merck, Pfizer, and UpToDate. Dr. Marr has received research support from Astellas, Merck, and Pfizer. Dr. Zhang has received research support from IBIS Biosciences/Abbott Molecular and AdvanDx Corp. Dr. Roos has received personal compensation in an editorial capacity for Seminars in Neurology.

\section{Antipsychotic efficacy and motor tolerability in a Phase III placebo-controlled study of pimavanserin in patients with Parkinson's disease psychosis (ACP-103-020)}

Jeffrey Cummings, MD, FAAN; Stuart Isaacson, MD; Roger Mills, MD; Hilde Williams; Kathy Chi-Burris; Daun Bahr; Rohit Dhall, MD; Clive Ballard, MD

OBJECTIVE: A PhIII outpatient study, optimized to reduce placebo response, was conducted to assess the efficacy and safety of pimavanserin in Parkinson's disease psychosis (PDP). BACKGROUND: PDP is frequent, distressing and a leading cause of institutionalization. It also complicates PD management and has been linked to increased morbidity, incident dementia and mortality. Current antipsychotics lack efficacy and/or have considerable tolerability and safety concerns. Pimavanserin, a selective non-dopaminergic $5-\mathrm{HT}_{2 \mathrm{~A}}$ receptor antagonist, has shown antipsychotic effects and good tolerability in previous Phase III trials, but a robust placebo effect precluded statistical separation. DESIGN/METHODS: Following 2-weeks screening, in which brief (non-pharmacological) psychosocial therapy adapted for PD (BPST-PD) was offered, 199 non-demented patients with moderate to severe psychosis (and on stable PD medication) were randomized to once-daily oral doses of $40 \mathrm{mg}$ pimavanserin or placebo $(1: 1)$ for 6 weeks. RESULTS: Pimavanserin met the primary endpoint using SAPS-PD (a PD-adapted version of the Scale for Assessment of Positive Symptoms, assessed by independent raters): -5.79 PIM vs -2.73 PBO change from Baseline at Day 43 (LSM difference $=-3.06 ; \mathrm{p}=0.001)$. These results were supported by highly significant improvement in the secondary efficacy measure, CGI-Improvement (LSM difference -0.67; $\mathrm{p}=0.001$ ), which was assessed by site investigators blinded to the SAPS-PD. Additionally, clinical benefits were observed in all exploratory efficacy measures with significant improvements in nighttime sleep, daytime wakefulness, and caregiver burden. Consistent with previous studies, pimavanserin met the key secondary endpoint for noninferiority to placebo on motor function (using UPDRS II+III) and was otherwise safe and well tolerated. The most common AEs were UTI (11.7\% PBO, 13.5\% PIM) and falls (8.5\% PBO, 10.6\% PIM). The only serious AEs that occurred in more than one patient were UTI (1-PBO, 3-PIM) and psychotic disorder (0-PBO, 2-PIM). CONCLUSIONS: These data suggest that pimavanserin is effective, safe and well-tolerated for PDP. Utility in other neuropsychiatric disorders remains to be explored.

Study Supported By: ACADIA Pharmaceuticals, Inc.

Disclosures: Dr. Cummings has received personal compensation for activities with Abbott, Acadia, Acerra ADAMAS, Anavex, Astellas, Avanir, Baxter, Bristol-Myers Squibb, Eisai, Elan, EnVivo, Forest, Genentech, GlaxoSmithKline, Janssen, Lilly, Lundbeck, Medivation, Medtronics, Merck, Merz, Neurokos, Novartis, Pfizer, Prana, QR, Sonexa, Takeda, and Toyama. Dr. Cummings holds stock and/or stock options in ADAMAS, Prana, Sonexa, MedAvante, Neurotrax, Neurokos, and QR pharma. Dr. Isaacson has received personal compensation for activities with Acadia, Allergan, Chelsea, GE, GSK, Ipsen, Lundbeck, Merz, Novartis, Teva, UCB, and US World Meds. Dr. Isaacson has received research support from Acadia, Adamas, Addex, Allergan, Biotie, Chelsea, GSK, Ipsen, Merck, Merz, Michael J Fox Foundation, NIH, Novartis, Santhera, Schering-Plough, Santhera, Serono, Teva, and UCB. Dr. Mills has received personal compensation for activities with ACADIA Pharmaceuticals Inc. as an employee. Ms. Williams has received personal compensation for activities with ACADIA Pharmaceuticals Inc. as an employee. Ms. Chi-Burris has received personal compensation for activities with ACADIA Pharmaceuticals Inc. as an employee. Mr. Bahr has 
received personal compensation for activities with ACADIA Pharmaceuticals Inc. as an employee. Dr. Dhall has received personal compensation for activities with UCB Pharma and Impax Pharmaceuticals. Dr. Ballard has received personal compensation for activities with Acadia, Lundbeck, Bristol-Myers Squibb, Novartis, and Bial Pharmaceuticals. Dr. Ballard has received research support from Lundbeck and Novo Nordisk.

\section{A phase 2, placebo-controlled, randomized, double-blind trial of tozadenant (SYN-115) in patients with Parkinson's disease with wearing-off fluctuations on levodopa $\quad C$. Olanow, MD, FAAN; Robert Hauser, MD, MBA, FAAN; Karl Kieburtz, MD, FAAN; Ann Neale, RN, BSN; Chris Resburg; Uwe Meya, MD;} Stephen Bandak, MB, BS, MRCP

OBJECTIVE: To evaluate the safety and efficacy of tozadenant as an adjunct to levodopa in PD patients with wearing-off fluctuations and determine dosages for phase 3 trials. BACKGROUND: Tozadenant is an oral, selective adenosine 2-alpha receptor antagonist. DESIGN/METHODS: This was an international, 12-week, double-blind, phase 2 trial in which patients on stable dosages of levodopa with at least $2.5 \mathrm{hr}$ of OFF time/day were randomized to tozadenant $60,120,180 \mathrm{or}$ $240 \mathrm{mg}$ BID, or matching placebo. Primary outcome measure was change from baseline to Week $12 \mathrm{in} \mathrm{hr/day} \mathrm{spent} \mathrm{in} \mathrm{the} \mathrm{OFF} \mathrm{state.} \mathrm{A} \mathrm{mixed-model} \mathrm{repeated-measures} \mathrm{ANCOVA} \mathrm{was} \mathrm{used} \mathrm{for}$ analyses with a prespecified hierarchical step-down approach to test multiple dose groups. RESULTS: Of 420 patients randomized, 337 completed treatment: mean age, $63.3 \mathrm{yr}$; P duration, $8.7 \mathrm{yr}$; baseline OFF time, $\sim 6 \mathrm{hr}$. Significant reductions in mean placebo-corrected change from baseline in OFF time were observed with tozadenant (mITT population) $120 \mathrm{mg}$ BID (-1.1 hr, $\mathrm{p}=0.0039)$ and $180 \mathrm{mg}$ BID $(-1.2 \mathrm{hr}, \mathrm{p}=0.0039)$. ON time with troublesome dyskinesia was not significantly increased in any tozadenant group. Mean placebo-corrected UPDRS III scores significantly improved with tozadenant $120 \mathrm{mg}$ BID $(-2.2, \mathrm{p}=0.0325)$ and $180 \mathrm{mg}$ BID $(-2.5, \mathrm{p}=0.0325)$. Mean placebo-corrected UPDRS I-III scores improved significantly in all tozadenant groups (all groups, $\mathrm{p} \leq 0.03$ ) as did mean placebo-corrected CGI-I and CGI-S scores. PGI-I scores significantly improved in the $120 \mathrm{mg}$ BID group. Most common AEs in the combined tozadenant groups were dyskinesia, nausea, dizziness, constipation, PD worsening, insomnia, and falls. CONCLUSIONS: Tozadenant, at a daily dosage of 120 or $180 \mathrm{mg}$ BID, was generally well tolerated and demonstrated efficacy in reducing OFF time and improving motor signs without significantly increasing troublesome dyskinesia. These two dosages can be considered for future trials.

Study Supported By: Biotie Therapies, Inc.

Disclosures: Dr. Olanow has received personal compensation for activities with Teva/Lundbeck, Novartis/ Orion, Ceregene, Clintrex, Biotie, Ipsen, Impax, and Abbott. Dr. Olanow has received personal compensation in an editorial capacity for the Journal Movement Disorders. Dr. Olanow holds stock and/or stock options in Clintrex and Ceregene. Dr. Hauser has received personal compensation for activities with Abbot Laboratories, Allergan, Inc., AstraZeneca, Biotie Therapeutics Inc., Ceregene, Inc., Chelsea Therapeutics, Inc., GE Healthcare, Impax Laboratories, Inc., Ipsen Biopharmaceuticals, Inc., Lundbeck, Merck/MSD, Noven Pharmaceuticals, Inc., Straken Pharmaceuticals, Ltd., Targacept, Inc., Teva Pharmaceuticals Industries, Ltd., Teva Neuroscience, Inc., Upsher-Smith Laboratories, UCB, Inc., UCB Pharma SA, and Xenoport, Inc. Dr. Kieburtz has received personal compensation for activities with the United States Food and Drug Administration, the Veteran's Administration and the National Institutes of Health (NINDS), Abbott, Acorda, Aptiv, Biogen Idec, Biotie Therapies, Biovail, Boehringer Ingelheim, Ceregene, Civitas, Clintrex, Cynapsus, Eli Lilly, EMD Serono, Genzyme, Impax, Intec, Ipsen, Isis, Knopp, Link Medicine, Lundbeck, LZ Therapeutics, Merz, Novartis, Orion, Otsuka, Pharma2b, Phytopharm, Schering Plough, Siena Biotech, Synosia, Solvay, Synagile, Teva, UCB Pharma, Vaccinex, Vectura, Xenoport. In addition, he has acted as a legal consultant to Pfizer, Thompson Hine, and the Welding Rod Litigation Defendants.Clintrex LLC partner. Dr. Kieburtz has received research support from National Institutes of Health (NEI, NINDS, NIA NICHD), the Michael J Fox Foundation, Medivation, NeuroSearch, and Pfizer. Ms. Neale has received personal compensation for activities with Biotie Therapies, Inc. Mr. Resburg has received personal compensation for activities with Biotie Therapies, Inc. Dr. Meya has received personal compensation for activities with Biotie Therapies, Inc. Dr. Bandak has received personal compensation for activities with Biotie Therapies, Inc. Dr. Bandak has received compensation for serving as director of Hapten Sciences.

\section{A placebo controlled, randomized, double-blind study to assess the safety and clinical benefit of rasagiline as an add-on therapy to dopamine agonist monotherapy in early Parkinson's disease (PD): The ANDANTEstudy Robert} Hauser, MD, MBA, FAAN; Dee Silver, MD; Azhar Choudhry, MD; Stuart Isaacson, $M D$ OBJECTIVE: Determine the efficacy and safety of rasagiline add-on therapy for early-PD patients sub-optimally controlled by dopamine agonist (DA) monotherapy. BACKGROUND DAs are often used as initial symptomatic therapy for early-PD. With disease progression, DA monotherapy can become suboptimal, requiring increasing dose to maintain efficacy. However increasing DA dose is associated with a higher risk of Adverse Events (AEs) (Antonini et a PMID:19709931). Rasagiline is a selective, irreversible MAO-B inhibitor that reduces striatal dopamine catabolism, and this distinct mode of action provides a rationale for add-on therapy to DAs for additional symptomatic benefit. DESIGN/METHODS: ANDANTE is a PhaseIV, 18-week study of PD patients (Hoehn \& Yahr 1-3) aged $\geq 30$ years taking stable DA dosages of $\geq 6 \mathrm{mg} /$ day ropinirole or $\geq 1.0 \mathrm{mg} /$ day pramipexole with suboptimal symptom control. Patients were randomized to rasagiline $1 \mathrm{mg}$ or placebo; DA dosage remained stable throughout. Primary outcome: change from baseline in total-UPDRS score. Secondary outcomes: changes from baseline in UPDRS activities of daily living (ADL) and motor scores, and CGI-I. Safety was assessed by AE frequency and severity, and discontinuation due to AEs. 328 patients were randomized, and 321 patients (mean age 62.6; duration PD 2.13 years) were included in the efficacy analysis. RESULTS: Treatment with add-on rasagiline resulted in a significant improvement in total-UPDRS score vs. placebo (Primary endpoint: treatment effect \pm SE $-2.4 \pm 0.95(95 \%$ CI $-4.3,-0.5, p=0.012)$. Rasagiline also significantly improved UPDRS-motor scores $(\mathrm{p}=0.007)$. There were no significant differences between groups for UPDRS-ADL $(\mathrm{p}=0.301$ ) or CGI-I scores. Rasagiline was well-tolerated, with no significant difference in percentage of patients with AEs (64.2\% vs. 61.0\%) or serious $\mathrm{AEs}(4.9 \%$ vs. $3.0 \%$ ) vs. placebo. Only 11 patients required rescue with levodopa during the study. CONCLUSIONS: Addition of rasagiline significantly improved motor symptoms in patients sub- optimally controlled with DA monotherapy, and was safe and well-tolerated with an AE profile similar to placebo.

Study Supported By: Teva Pharmaceuticals Inc.

Disclosures: Dr. Hauser has received personal compensation for activities with Abbott Laboratories, Allergan, Inc., AstraZeneca, Biotie Therapeutics Inc., Ceregene, Inc., Chelsea Therapeutics, Inc., GE Healthcare, Impax Laboratories, Inc., Ipsen Biopharmaceuticals, Inc., Lundbeck, Merck/MSD, Noven Pharmaceuticals, Inc., Straken Laboratories, Inc., Ipsen Biopharmaceuticals, Inc., Lundbeck, Merck/MSD, Noven Pharmaceuticals, Inc., Straken
Pharmaceuticals, Ltd., Targacept, Inc., Teva Pharmaceuticals Industries, Ltd., Teva Neuroscience, Inc., UpsherSmith Laboratories, UCB, Inc., UCB Pharma SA, and Xenoport, Inc. Dr. Silver has received personal compensation for activities with Boehringer-Ingelheim, Teva Neuroscience, GlaxoSmithKline, Novartis Pharmaceuticals, Kyowa Pharmaceuticals, Ipsen, Pfizer Inc, Johnson \& Johnson, MDS Pharma Services, Accera Pharma, Forest Pharmaceuticals, Innovex Pharmaceuticals, Merz Pharma, UCB Biosciences. Dr. Silver has received research support for clinical trials. Dr. Choudhry has received personal compensation for activities with Teva Pharmaceuticals. Dr. Isaacson has received personal compensation for activities with Acadia, Allergan, Chelsea, GE, GSK Ipsen, Lundbeck, Merz, Novartis, Teva, UCB, and US World Meds. Dr. Isaacson has received research support from Acadia, Adamas, Addex, Allergan, Biotie, Chelsea, GSK, Ipsen, Merck, Merz, Michael J Fox Foundation, NIH, Novartis, Santhera, Schering-Plough, Santhera, Serono, Teva, and UCB.

\section{Davunetide for progressive supranuclear palsy: Results of the AL-108-231, phase 2/3, 52 week, multi-center, randomized, double-blind, placebo-controlled clinical}

trial Adam Boxer, MD, PhD; Anthony Lang, MD, FAAN; Murray Grossman, MD, FAAN; David Knopman, MD, FAAN; Bruce Miller, MD, FAAN; Lon Schneider, MD; Rachelle Doody, MD, PhD, FAAN; Andrew Lees, MD, FRCP; Joe Hirman; Bruce Morimoto; Michael Gold, $M D$

OBJECTIVE: To evaluate the efficacy and safety of davunetide for the treatment of PSP. BACKGROUND: Davunetide (AL-108) is an 8 amino acid peptide that promotes microtubule stability, decreases tau phosphorylation and improves memory in pre-clinical studies. Since PSP is tightly linked to tau pathology, we hypothesized that davunetide would be an effective treatment for PSP. DESIGN/METHODS: A double-blind, parallel group, clinical trial of davunetide $30 \mathrm{mg}$ or matched placebo (randomized 1:1) administered intranasally twice daily for 52 weeks was conducted at 47 centers in North America, Europe and Australia. Participants were required to meet NINDS-SPSP criteria for possible or probable PSP, and were allowed to remain on stable doses of levodopa or coenzyme Q10. Co-primary outcomes were the PSP Rating Scale (PSPRS) and Schwab and England ADL (SEADL) scale. Safety was assessed by adverse events (AEs) and routine laboratory tests. Secondary outcomes included the Clinical Global Impression of Change (CGIC) and the change in brain atrophy on MRI. RESULTS: 360 participants were screened, 313 were randomized and $243(77.6 \%)$ completed the study. Baseline demographics and disease severity were similar between treatment groups. Mean age was $68 \pm 6.6$, baseline PSPRS score was $40 \pm 11$ and $94.2 \%$ (of 244 with available data) had the $\mathrm{H1} / \mathrm{H} 1$ tau haplotype. There were no differences between davunetide and placebo-treated groups at 52 weeks in the PSPRS $(\mathrm{p}=0.41)$ or SEADL $(\mathrm{p}=0.92)$ scores. Mean PSPRS change was approximately $11 \pm 9$ overall. There were also no group differences in CGIC scores $(\mathrm{p}=0.26)$ or MRI ventricular volumes $(\mathrm{p}=0.77 ; \mathrm{n}=215)$. There were 10 deaths in the davunetide group and 8 in the placebo group, with 54 serious AEs in each. Nasal AEs were more frequent in the davunetide group. CONCLUSIONS: Davunetide is not an effective treatment for PSP. PSP clinical trials are feasible and should be pursued with other promising tau-directed therapies.

Study Supported By: Allon Therapeutics.

Disclosures: Dr. Boxer has received personal compensation from BMS, Plexxikon and Phloronol for consulting Dr. Boxer has received research support from Elan, Forest, Genentech, Medivation, BMS, Janssen and Pfizer Pharmaceuticals. Dr. Lang has received personal compensation for activities with Abbott, Allon Therapeutics, Astra Zenica, Avanir Pharmaceuticals, Biogen Idec, Biovail, Boerhinger-Ingelheim, Cephalon, Ceregene, Eisai, GSK, Lundbeck A/S, Medrronic, Merck Serono, Merke, Novartis, and Teva. Dr. Lang has received royalty payments from Saunders, Wiley-Blackwell, Johns Hopkins Press, and Cambridge University Press. Dr. Grossman payments from Saunders, Wiley-Blackwell, Johns Hopkins Press, and Cambridge University Press. Dr. Grossman
has received personal compensation for activities with Allon Therapeutics. Dr. Knopman has received personal compensation for activities with Lilly Pharmaceuticals, TauRx, and Allon Pharmaceuticals. Dr. Knopman has received personal compensation in an editorial capacity for Neurology. Dr. Knopman has received research support from Janssen and Baxter. Dr. Miller has received personal compensation for activities with Allon Therapeuctics, Inc.; TauRx Therapeutics, Ltd. Dr. Miller has received research support from Novartis. Dr. Schneider has received personal compensation for activities with Allon, Astra Zeneca, Forest Laboratories Dr. Schneider has received personal compensation for activities with Allon, Astra Zeneca, Forest Laboratories,
Eli Lilly GSK, Johnson and Johnson, Medivation, Merck, Myriad, Sanofi-Aventis, Takeda, Voyager, and Wyeth Eli Lilly GSK, Johnson and Johnson, Medivation, Merck, Myriad, Sanofi-Aventis, Takeda, Voyager, and Wyeth
pharmaceuticals. Dr. Schneider has received research support from Myriad pharmaceuticals. Dr. Doody has received personal compensation for activities with Allon, AC Immune, Accera, AZTherapies, Biote, Cardeus Chiesi, Genzyme, Hoffman-LaRoche, Merck, Nutricia, Shire, Sonexa, Suven, Takeda, Toyama, and Zinfandel. Dr. Doody has received research support from Avanir, Jannsen AD Immunotherapy, Genentech, Pfizer, and Eli Lilly. Dr. Lees has received personal compensation for activities with Allon, Genus, Novartis, Teva, Meda Boehringer Ingelheim, GlaxoSmithKline, Ipsen, Lundbeck, Allergan, Orion, BIAL, Noscira and Roche. Dr. Lees has received research support from the PSP Association and Weston Trust - The Reta Lila Howard Foundation Dr. Hirman has received personal compensation for activities with Allon. Dr. Morimoto has received personal compensation for activities with Allon. Dr. Gold has received personal compensation for activities with Allon.

\section{Interim analysis of 12 patients with amyotrophic lateral sclerosis (ALS) treated with autologous differentiated mesenchymal stem cells: Preliminary} data of a Phase I/II clinical trial Dimitrios Karussis, $M D, P h D$ Panayiota Petrou; Daniel Offen; Marc Gotkine, MD; Zohar Argov, MD; Adi Vaknin-Dembinsky, MD; Ibrahim Kassis; Tamir Ben-Hur, MD, PhD; Eldad Melamed, MD OBJECTIVE: To evaluate the safety and tolerability of treatment with autologous mesenchymal stem cells differentiated to secrete neurotrophic factors (MSC-NTF) in ALS patients utilizing the intramuscular(IM) and the intrathecal(IT) way of administration. BACKGROUND A previous study from our group at Hadassah has shown the safety of IV/IT administration of unmodified MSC in ALS patients. MSC-NTF demonstrated neuroprotective effects in various animal models of neurodegenerative diseases, including ALS. DESIGN/METHODS: This Phase I/II clinical study will include upon completion 24 ALS patients. Twelve participants have already been recruited. MSC were isolated from the patients' own bone marrow, expanded ex-vivo and induced to differentiate into MSC-NTF secreting GDNF and BDNF. Autologous MSC-NTF cells were transplanted, by IM (at 24 sites:200,000 cells per site) or IT ( $1 \times 10^{6}$ cells/ 
$\mathrm{kg}$ ) injections to patients with early (ALSFRS score of $>30 ; \mathrm{n}=6$ ) or advanced ALS (ALSFRS $15-30 ; n=6$ ), respectively. Patients were followed up clinically on a monthly basis for a pretreatment period of 3 months and for 6 months post-transplantation. Respiratory function tests, 3D-MRI of the muscles and compound muscle action potential amplitudes at 3 sites were used as additional surrogate markers of disease activity. RESULTS: During the six-month follow-up of the transplanted patients, no serious treatment-related adverse events were observed, indicating a short-term treatment safety. The clinical follow-up of the patients revealed initial indications of beneficial clinical effects in the MSC-NTF transplanted patients, as evidenced by a significant change in the rate of clinical progression (ALSFRS), in the respiratory function, in electrophysiology and in the 3D-MRI volumetric evaluation of the muscles, as compared to the 3 months preceding the treatment. CONCLUSIONS: Preliminary results of our ALS trial with autologous IM/IT MSC-NTF transplantation indicate that the used treatment protocols appear to be safe. Further analysis of the accumulated data and longer follow up of the participating patients are needed to confirm these observations.

Study Supported By: The study is sponsored by Brainstorm Cell Therapeutics Ltd. Disclosures: Dr. Karussis has received personal compensation for activities as a speaker and an advisory board member. Dr. Petrou has nothing to disclose. Dr. Offen has received personal compensation for activities with Brainstorm Cell Therapeutics. Dr. Gotkine has nothing to disclose. Dr. Argov has nothing to disclose. Dr. Dembinsky-Vaknin has nothing to disclose. Dr. Kassis has nothing to disclose. Dr. Ben-Hur has received personal compensation for activities with Brain Watch and Regenera Pharma. Dr. Melamed has received personal compensation for activities with Brainstorm Cell Therapeutics.

\section{A Study to Evaluate Efficacy, Safety and Tolerability of Single Doses of Tirasemtiv in Patients with Myasthenia} Gravis Donald Sanders, MD, FAAN; Jeffrey Rosenfeld, PhD, MD, FAAN; Mazen Dimachkie, MD, FAAN; Lisa Meng; Fady Malik; Tirasemtiv in Myasthenia Gravis Study Group

OBJECTIVE: To determine the effect of single doses of tirasemtiv on measures of skeletal muscle function and fatigability in patients with generalized MG. BACKGROUND: Tirasemtiv (formerly CK-2017357) is a fast skeletal troponin activator that sensitizes the sarcomere to calcium, thus increasing muscle force following sub-maximal neuronal input and reducing fatigability. In an animal model of myasthenia gravis (MG), single doses of tirasemtiv improved muscle force and reduced fatigability in situ while increasing grip strength (Nat Med. $2012 \mathrm{Feb}$ 19;18(3):452-5). DESIGN/METHODS: 32 patients with AChR-antibody positive MG and muscle weakness were recruited. In a double-blind random treatment sequence, each patient received single doses of tirasemtiv $250 \mathrm{mg}$, tirasemtiv $500 \mathrm{mg}$, and placebo; each dose was separated by at least one week. Outcome measures included the Quantitative MG Score (QMG), MG Composite (MGC) and Manual Muscle Testing, Modified MG Symptom Score, and Global Assessment by patient and investigator. RESULTS: Six hours after dosing, improvements in the QMG were statistically significant and related to the tirasemtiv dose $(-0.49$ QMG points per $250 \mathrm{mg} ; \mathrm{p}=0.02$ ). Also at six hours after dosing, increases in the percent predicted forced vital capacity were statistically significantly related to the dose level $(2.2 \%$ per $250 \mathrm{mg} ; \mathrm{p}=0.04$ ), as were the individual comparisons of each tirasemtiv dose level versus placebo. QMG score improved at least 3 points in twice as many patients after $500 \mathrm{mg}$ than after placebo $(\mathrm{p}=0.098)$. Both doses of tirasemtiv were well-tolerated; there were no premature terminations or serious adverse events. The most commonly reported adverse event was dizziness, which was mild in all but one case, which was classified as moderate. CONCLUSIONS The results of this study suggest that tirasemtiv may improve function in MG and will be used to support further development of tirasemtiv in neuromuscular diseases.

Study Supported By: This trial was supported by the NINDS under Award Number 1RC3NS070670 - 01 (F.I.M)

Disclosures: Dr. Sanders has received personal compensation for activities with Athena Diagnostics, Accordant Health Services, Jacobus Pharmaceuticals, CytoKinetics, GSK, Alexion, UCB as a speaker or consultant. Dr. Rosenfeld has received personal compensation for activities with Avanir Pharmaceuticals, Cytokinetics, Hill-Rom, Inc.,Gerson Lehrman Group and Guidepoint Global. Dr. Rosenfeld has received research support from Hill-Rom, Inc. Dr. Dimachkie has received personal compensation for activities with Pfizer, Depomed, Merck, CSL-Behring, and Biomarin LEMS as a speaker, advisory board member, or steering committee member. Dr. Meng has received personal compensation for activities with Cytokinetics, Inc. Dr. Malik has received personal compensation for activities with Cytokinetics, Inc. Tirasemtiv in Myasthenia Gravis Study Group has nothing to disclose.

\section{Droxidopa Treatment Impact on Orthostatic Symptoms and Standing Systolic Blood Pressure in Patients with Parkinson's Disease (PD) and Symptomatic Neurogenic Orthostatic Hypotension (NOH) Stuart Isaacson, MD; Robert} Hauser, MD, MBA, FAAN; Cameron Szakacs, PhD; Christopher Cioffi, PhD

OBJECTIVE: Evaluate clinical efficacy and safety of droxidopa as demonstrated by changes in Orthostatic Hypotension Questionnaire (OHQ), dizziness/lightheadedness (Orthostatic Hypotension Symptom Assessment Item 1), standing systolic blood pressure (SBP), and falls. BACKGROUND: Autonomic dysfunction is common in PD. Approximately $18 \%$ of patients with PD develop symptomatic NOH. ${ }^{1} \mathrm{NOH}$ results from failure of the autonomic nervous system to respond to changes in posture due to an inadequate release of norepinephrine (NE). ${ }^{2}$ Droxidopa is an oral pro-drug converted to NE. DESIGN/METHODS Patients were randomized to placebo or droxidopa (Study 306); dose titrated to $100-600 \mathrm{mg}$ TID over a 2-week double-blind period, followed by 8 weeks of double-blind treatment. Change in dizziness/lightheadedness from baseline to Week 1 was the primary efficacy measure. Secondary outcome measures included change in OHQ, standing SBP, and falls. Study 306 was separated into two parts following an interim analysis; 306A ( $=51)$ and 306B $(n=174)$. Meta-analyses were performed to evaluate efficacy and safety of all patients $(\mathrm{n}=225, \mathrm{mITT}: \mathrm{n}=197)$. RESULTS: Droxidopa patients experienced significant improvement in dizziness/lightheadedness at Week 1 compared to placebo (1.2 unit difference; $\mathrm{p}=0.008$ ), and showed a trend toward improvement at Week 8 ( 0.8 unit difference; $\mathrm{p}=0.077$ ). Standing SBP significantly improved with droxidopa compared to placebo at
Week $1(6.8 \mathrm{mmHg} ; \mathrm{p}=0.014)$, and showed a numerical improvement at Week 8 $(2.2 \mathrm{mmHg} ; \mathrm{p}=0.414)$. Droxidopa also improved symptoms and symptom impact compared to placebo as evaluated by OHQ. Droxidopa patients experienced a rate of falls/patient/week of 0.38 vs. 1.73 for those on placebo, a $78 \%$ reduction $(\mathrm{p}=\mathrm{NS})$. The most common $(>5 \%)$ adverse events associated with droxidopa treatment included headache, dizziness, hypertension, nausea, and fatigue. CONCLUSION: Droxidopa treatment improved signs and symptoms of $\mathrm{NOH}$ associated with $\mathrm{PD}$, including dizziness/lightheadedness and standing SBP. Droxidopa was safe and well tolerated. 1. Ha et al. Parkinsonism Relat Disord.2001; 17:625-8. 2. Freeman R. N Engl J Med.2008;358:615-24.

Study Supported By: Chelsea Therapeutics. Disclosures: Dr. Isaacson has received personal compensation for activities with Acadia, Allergan, Chelsea,
GE, GSK, Ipsen, Lundbeck, Merz, Novartis, Teva, UCB, and US World Meds. Dr. Isaacson has received research support from Acadia, Adamas, Addex, Allergan, Biotie, Chelsea, GSK, Ipsen, Merck, Merz, Michael J Fox Foundation, NIH, Novartis, Santhera, Schering-Plough, Santhera, Serono, Teva, and UCB. Dr. Hauser has received personal compensation for activities with Abbott Laboratories, Allergan, Inc., AstraZeneca, Biotie Therapeutics Inc., Ceregene, Inc., Chelsea Therapeutics, Inc., GE Healthcare, Impax Laboratories, Inc., Ipsen Biopharmaceuticals, Inc., Lundbeck, Merck/MSD, Noven Pharmaceuticals, Inc., Straken Pharmaceuticals, Ltd., Targacept, Inc., Teva Pharmaceuticals Industries, Ltd., Teva Neuroscience, Inc., Upsher-Smith Laboratories, UCB, Inc., UCB Pharma SA, and Xenoport, Inc. Dr. Szakacs has received personal compensation for activities with Chelsea Therapeutics as an employee. Dr. Cioffi has received personal compensation for activities with Chelsea Therapeutics as an employee. Dr. Cioffi's father holds stock and/or stock options in IBM.

\section{IMS-III Like Subgroup Analysis in the North American SOLITAIRE Stent-Retriever Acute Stroke Registry Osama} Zaidat, MD, FAAN; Alicia Castonguay, PhD; Rishi Gupta, MD; Chung-Huan Sun, MD; Coleman Martin, MD; William Holloway, MD; Nils Mueller-Kronast, MD; Joey English, MD, PhD; Italo Linfante, MD; Dabus Guilherme, MD; Tim Malisch, MD; Franklin Marden, MD, FAAN; Hormozd Bozorgchami, MD; Andrew Xavier, MD; Ansaar Rai; Michael Froebler, MD, PhD; Aamir Badruddin, MD; Thanh Nguyen, MD; M. Asif Taqi, MD; Michael Abraham, MD; Vallabh Janardhan, MD; Hashem Shaltoni, MD; Albert Yoo; Gavin Britz, MD; Peng Chen; Alex Abou-Chebl, MD; Ashish Nanda, MD; Ritesh Kaushal, MD, PhD; Mohammad Issa, MD; Raul Nogueira, MD OBJECTIVE: To present the clinical and angiographic outcomes of IV-rtPA plus thrombectomy using a newer generation device from the North American SOLITAIRE-FR Stent-Retriever Acute Stroke (NASA) Registry. BACKGROUND: IMS-III demonstrated no significant difference between treatment with IV-rtPA alone or IV-rtPA plus IA therapy. However, the trial included only earlier generations of thrombectomy devices and did not evaluate the efficacy of newer devices. DESIGN/METHODS: The investigator-initiated NASA Registry recruited sites within North America to submit data on consecutive patients treated with Solitaire-FR. A cohort similar to the IMS-III IV-rtPA+Solitaire-FR population was identified and compared to those receiving Solitaire-FR alone. SICH was defined as any parenchymal hematoma, SAH, or IVH associated with a worsening of the NIHSS score by 4 or more within 24 hours. Successful recanalization was defined as TIMI $\geq 2$. Good clinical outcome was defined as a 90-day $\mathrm{mRS} \leq 2$. RESULTS: 334 patients underwent treatment using the SOLITAIRE-FR device in 23 centers. Mean age was 67.3 15.1 years; mean NIHSS was 18 (IQR 14-23). Of those, $44 \%(147 / 333)$ were treated with IV-rtPA+Solitaire-FR versus 56\% (186/333) with SolitaireFR alone. Recanalization rate was $86.4 \%$ (127/147) in the IV-rtPA+Solitaire-FR versus $82.3 \%$ $(153 / 186)$ in the SOLITAIRE-FR only group $(\mathrm{p}=0.4)$. sICH was noted in $11 \%(16 / 146)$ of IV-rtPA+Solitaire-FR patients compared to $9.2 \%(17 / 185)$ in the Solitaire-FR group $(\mathrm{p}=0.7)$. In IV-rtPA+Solitaire-FR patients with available outcomes, 52\% (66/127) had achieved a 90-day good clinical outcome versus $35.6 \%(57 / 160)$ of patients treated with Solitaire-FR alone $(\mathrm{p}=0.006$ ). Mortality was $25 \%(33 / 132)$ in the IV-rtPA+Solitaire-FR versus $35.4 \%(58 / 164)$ in Solitaire-FR alone groups $(\mathrm{p}=0.06)$. CONCLUSIONS: In the NASA registry, the IMS-II like group (IV-rtPA+Solitaire-FR) demonstrated a higher rate of good clinical outcome versus treatment with Solitaire alone and a trend towards reduced mortality.

Study Supported By: N/A

Disclosures: Dr. Zaidat has received personal compensation for activities with Boston Scientific Corporation and Micrus Inc. Dr. Castonguay has nothing to disclose. Dr. Gupta has received personal compensation for activitie with Stryker Neurovascular, Rapid Medical, Reverse Medical, and Covidien. Dr. Gupta has received personal compensation in an editorial capacity with the Journal of Neuroimaging. Dr. Sun has nothing to disclose. Dr. Martin has nothing to disclose. Dr. Holloway has nothing to disclose. Dr. Mueller-Kronast has nothing to disclose. Dr. English has received personal compensation in an editorial capacity for Harrison's Practice. Dr. Linfante has received personal compensation for activities with Micrus Corporation and Codman Neurovascular as a con-
sultant. Dr. Linfante has received research support from Surpass Medical Inc. Dr. Guilherme has nothing to disclose. sultant. Dr. Linfante has received research support from Surpass Medical Inc. Dr. Guilherme has nothing to disclose,
Dr. Malisch has nothing to disclose. Dr. Marden has nothing to disclose. Dr. Bozorgchami has nothing to disclose. Dr. Xavier has received personal compensation for activities with Concentric as a consultant. Dr. Rai has received personal compensation for activities with Concentric Medical as a speaker. Dr. Froehler has nothing to disclose. Dr. Badruddin has nothing to disclose. Dr. Nguyen has nothing to disclose. Dr. Taqi has nothing to disclose. Dr. Abraham has nothing to disclose. Dr. Janardhan has nothing to disclose. Dr. Shaltoni has nothing to disclose. Dr. Yoo has received research support from Penumbra Inc. Dr. Britz has nothing to disclose. Dr. Chen has nothing to disclose. Dr. Abou-Chebl has received personal compensation for activities with Bristol-Myers Squibb Company/Sanofi-Aventis Pharmaceuticals, Inc., and Codman Inc. Dr. Nanda has nothing to disclose. Dr. Kaushal has nothing to disclose. Dr. Issa has nothing to disclose. Dr. Nogueira has received personal compensation for activities with Concentric Medical, Inc. ev3 Neurovascular, Inc., Coaxia, Inc., and Rapid Medical, Inc.

Mutations in DEPDC5 cause Familial Focal Epilepsy with
Variable Foci and are a common cause of familial non-lesional focal epilepsy Massimo Pandolfo, MD; Leanne Dibbens; Boukje de Vries; Simona Donatello; Sarah Heron; Bree Hodgson; Satyan Chintawar; Douglas Crompton; James Hughes, MD; Susannah Bellows; Karl Martin Klein; Petra Callenbach; Mark Corbett; Alison Gardner; Sarah Kivity; Xenia Iona; Brigid Regan; Claudia Weller; Denis Crimmins, FRACP, MBBS; Terence O'Brien; Rosa GuerreroLópez; John Mulley; Francois Dubeau, MD; Laura Licchetta; Francesca Bisulli; Patrick 
Cossette, MD; Paul Thomas; Jozef Gecz; Jose Serratosa, MD, PhD; Oebele Brouwer; Frederick Andermann, MD, FRCPC, FAAN; Eva Andermann, $M D$, PhD; Arn van den Maagdenberg; Samuel Berkovic, MD, FRACP; Ingrid Scheffer

OBJECTIVE: To identify the genetic cause of autosomal dominant Familial Focal Epilepsy with Variable Foci (FFEVF), to investigate the prevalence of mutations in the FFEVF causative gene in familial cases of non-lesional focal epilepsy, to study the expression in the brain and the subcellular localization of the encoded protein. BACKGROUND: FFEVF is characterized by seizures arising from different cortical regions in different affected family members. Brain imaging is normal. Seizure onset varies from infancy to adult life. Affected individuals occasionally have neuropsychiatric co-morbidities. Linkage studies mapped FFEVF to chromosome 22q12, but the causative gene had so far eluded identification. DESIGN/METHODS: We applied exome sequencing to two FFEVF families previously linked to chromosome $22 \mathrm{q} 12$, identifying $D E P D C 5$ as the most likely candidate gene. We sequenced DEPDC5 in six additional 22q12-linked families and scanned DEPDC5 for sequence variation in 82 unrelated probands from families with at least two individuals with non-lesional focal epilepsy. We used qRT-PCR, immunofluorescence and western blot analysis to study DEPDC 5 expression and subcellular localization. RESULTS: Heterozygous mutations in DEPDC5 were identified in 7/8 FFEVF families linked to chromosome 22q12 and in 10/82 (12.2\%) probands from the small families with focal epilepsy. Each DEPDC5 mutation segregated with the FFEVF phenotype in the respective family and was absent in both dbSNP135 and an in-house exome sequencing database of 710 chromosomes. Most mutations caused premature termination codons suggesting haploinsufficiency as pathogenic mechanism. $D E P D C 5$ encodes a1604 amino acid protein of unknown function, probably implicated in modulation of intracellular signaling. Mouse Depdc5 transcripts were detected at low levels in all brain regions and throughout brain development. Immunofluorescence analyses in mouse and human brain showed specific expression in neurons and perinuclear localization. CONCLUSIONS: Our findings establish DEPDC5 mutations as the most common known cause of familial focal epilepsy and identify a novel pathogenic pathway for epilepsy.

Study Supported By: This work was supported by the National Health and Medical Research Council of Australia (Program Grant 628952 to S.F.B., I.E.S., L.M.D., P.Q.T. and J.G. Australia Fellowship 466671 to S.F.B., Senior Research Fellowship 508043 to J.G., Practitioner Fellowship 1006110 to I.E.S., Training Fellowship 1016715 to S.E.H. and Career Development Fellowship 1032603 to L.M.D.) and by the Center of Medical System Biology (CMSB) established by the Netherlands Genomics Initiative/Netherlands Organisation for Scientific Research (NGI/NWO) to A.v.d.M., the Netherlands Organization for Scientific Research (NWO, 94033-030) and the Dutch National Epilepsy Fund (98-14).

Disclosures: Dr. Pandolfo has received personal compensation for activities with Santhera (Liestal, Switzerland) as a speaker and Repilgen as a member of the monitoring board. Dr. Pandolofo has received royalty payments from Athena Diagnostic. Dr. Pandolfo has received research support from Repligen. Dr. Dibbens has nothing to disclose. Dr. de Vries has nothing to disclose. Dr. Donatello has nothing to disclose. Dr. Heron has nothing to disclose. Dr. Hodgson has nothing to disclose. Dr. Chintawar has nothing to disclose. Dr. Crompton has received disclose. Dr. Hodgson has nothing to disclose. Dr. Chintawar has nothing to disclose. Dr. Crompton has received
research support from UCB Pharma. Dr. Hughes has nothing to disclose. Dr. Bellows has nothing to disclose. Dr. Klein has nothing to disclose. Dr. Callenbach has received research support from UCB Pharma. Dr. Corbet has nothing to disclose. Dr. Gardner has nothing to disclose. Dr. Kivity has nothing to disclose. Dr. Iona has nothing to disclose. Dr. Regan has nothing to disclose. Dr. Weller has nothing to disclose. Dr. Crimmins has nothing to disclose. Dr. O'Brien has nothing to disclose. Dr. Guerrero-Lopez has nothing to disclose. Dr. Mulley has nothing to disclose. Dr. Dubeau has nothing to disclose. Dr. Licchetta has nothing to disclose. Dr. Bisulli has nothing to disclose. Dr. Cossette has nothing to disclose. Dr. Thomas has received research support from Pfizer. nothing to disclose. Dr. Cossette has nothing to disclose. Dr. Thomas has received research support from Pfizer,
Dr. Gecz has nothing to disclose. Dr. Serratosa has received personal compensation for activities with Eisai, UCB Pharma, and Bial. Dr. Brouwer has nothing to disclose. Dr. Andermann has nothing to disclose. Dr. van den Maagdenberg has nothing to disclose. Dr. Berkovic has received personal compensation for activities with GlaxoSmithKline and UCB Pharma. Dr. Berkovic has received research support from UCB Pharma, SciGen, and Sanofi-Aventis. Dr. Scheffer has nothing to disclose.

\section{A Multicentre, Randomised, Open-Label, Comparative Phase 4 Trial to Assess Changes in Dementia Diagnostic Category and Diagnostic Confidence after DaTscan Imaging in Subjects with an Uncertain Diagnosis of Dementia with Lewy Bodies (Possible DLB) Zuzana Walker,} Alessandro Padovani, MD; Alan Thomas; Fraser Inglis; Naji Tabet; Michael Rainer; Gilberto Pizzolato, MD; Emilio Moreno-Carretero

OBJECTIVE: To evaluate the impact of DaTscan ${ }^{\mathrm{TM}}$ SPECT imaging on dementia diagnostic category and on the diagnostic confidence of clinicians in patients with a diagnosis of possible DLB. BACKGROUND: A clinical diagnosis of Dementia with Lewy bodies (DLB) has good specificity but low sensitivity and is particularly challenging in patients with an uncertain diagnosis (possible DLB). DaTscan ${ }^{\mathrm{TM}}$ (Ioflupane ${ }^{123} \mathrm{I}$ ) is a radiopharmaceutical for single-photon emission computed tomography (SPECT) brain imaging to visualize the dopamine transporter receptors located on the presynaptic terminals of dopaminergic neurons. DESIGNS/METHODS: One hundred and eighty seven patients with a diagnosis of possible DLB were recruited from 23 centers in 6 European countries. Patients were randomized to have a DaTscan ${ }^{\mathrm{TM}}$ at baseline (127 patients; imaging group) or to have no-imaging (60 patients; control group). The proportion of patients with changes in clinical diagnosis (to probable DLB or non-DLB) and changes in the confidence in diagnosis from baseline was compared between the two groups at 8 and 24 weeks of follow-up. RESULTS: Significantly more patients in the DaTscan ${ }^{\mathrm{TM}}$ imaging group had a change in diagnostic category after 8 weeks $(62 \%$ vs $4 \% ; P<.0001)$ and after 24 weeks $(69 \%$ vs $16 \%$; $P<.0001)$ compared to patients in the control group. Additionally, significantly more patients in the imaging group were given more confident diagnoses at 8 and 24 weeks of follow-up $(P<.0001)$ compared to the control group. Clinicians were more likely to change the diagnostic category if the DaTscan ${ }^{\mathrm{TM}}$ was abnormal $(82 \%)$ than if the result was normal (48\%). CONCLUSIONS: DaTscan ${ }^{\mathrm{TM}}$ SPECT imaging significantly contributed to change diagnostic category and improve diagnostic confidence, proving to be a useful adjunct in the diagnosis of dementia in patients with possible DLB. Changes in diagnostic category were less frequent in the control group despite a six-month prospective follow-up.

Study Supported By: Study sponsored by GE Healthcare.

Disclosures: Dr. Walker has received personal compensation for activities with GE Healthcare, Bayer, and Novartis. Dr. Walker has received research support from GE Healthcare and Lundbeck. Dr. Padovani has nothing to disclose. Dr. Thomas has nothing to disclose. Dr. Inglis has received personal compensation for activities with Pfizer. Dr. Inglis has received research support from Abbott Laboratories Ltd, Eli-Lilly and Co, GE Healthcare, Genentech, Medivation Inc, Noscira, Pfizer, and Roche. Dr. Tabet has received personal compensation for activities with Eli Lilly, Pfizer, and GE Healthcare. Dr. Rainer has nothing to disclose. Dr. Pizzolato has nothing to disclose. Dr. Moreno-Carretero has received personal compensation for activities with GE Healthcare.

Neocortical ictal high frequency oscillations (HFO) are a surrogate marker of increased action potential firing rate and synchrony that discriminate the ictal focus from the penumbra Shennan Weiss, MD; Garrett Banks; Guy McKhann, MD; Robert Goodman; Ronald Emerson, MD, FAAN; Catherine Schevon, $M D ;$ Andrew Trevelyan

OBJECTIVE: To identify the cellular electrophysiological correlates of ictal high frequency oscillations in an effort to better identify the active seizure focus. BACKGROUND: Traditionally, the epileptogenic zone is characterized by the earliest and largest amplitude aberrant EEG activity in the $1-50 \mathrm{~Hz}$ spectrum correlated with a clinical event. However, large EEG signals may arise from either focal discharges or from large inhibitory synaptic currents present in surrounding territories which have not been incorporated into the seizure, and where neural firing is unstructured. Conventional EEG interpretation, therefore, cannot generally distinguish the core active regions from the surrounding territory. To overcome this ambiguity, we sought to test late-onset, sustained ictal high frequency oscillations (HFOs) as surrogate markers of ictal discharges in the underlying cortex. DESIGNS/METHODS: Four patients with neocortical epilepsy were implanted with a 96 channel micro-electrode array in or near the seizure onset zone. Simultaneous recordings were also performed using standard grids and strips of surface macroelectrodes to determine the seizure onset zone. We recorded ten seizures with video correlation and analyzed multi-unit (neuron) activity, high frequency oscillations, and standard EEG. RESULTS: We demonstrate that sustained, repetitive ictal HFOs detectible on the cortical surface by electrocorticography correlate well with the intense, hypersynchronized neuronal population firing bursts that are present in territories recruited into the seizure. Sustained HFOs are not present in penumbral areas where such bursting is notably absent. CONCLUSIONS: We conclude that ictal HFOs detected on the cortical surface are indicative of increased neuronal activation in the underlying cortex and can distinguish cortical regions recruited into a seizure from the penumbra.

Study Supported By: NIH K08 to Catherine Schevon MD, PhD; NIH R25 to Shennan Weiss MD, PhD.

Disclosures: Dr. Weiss has nothing to disclose. Dr. Banks has nothing to disclose. Dr. McKhann has nothing to disclose. Dr. Goodman has nothing to disclose. Dr. Emerson has received personal compensation for activities with Reach Bionics, Inc. as a consultant. Dr. Emerson holds stock and/or stock options in NeuroPace, Inc. Dr. Schevon has nothing to disclose. Dr. Trevelyan has nothing to disclose. Reduced $\triangle 5$-ADIOL in CSF and Plasma as a Biomarker
of Neurocognitive Impairment in HIV Infection Kaoru Saijo, MD, PhD; David J. Moore, MD; Ben Gouaux; Igor Grant, MD; Ronald Ellis, $M D, P h D$

OBJECTIVE: To determine whether plasma and CSF levels of $\Delta 5-\mathrm{ADIOL}$ are reduced in HIV+ with NCI. BACKGROUND: Microglial activation and related inflammatory responses have been demonstrated in HIV-associated neurocognitive impairment $(\mathrm{NCI})$ and may play a role in neuropathogenesis, even after combination antiretroviral therapies (cART) produce successful viral suppression and immune recovery. We evaluated a recently discovered pathway by which microglial inflammatory responses are downregulated, through binding of the endogenous neurosteroid 5-ANDROSTEN-3 $\beta, 17 \beta$-DIOL ( $\Delta 5$-ADIOL) to the estrogen receptor (ER) $\beta$. DESIGNS/METHODS: Participants: $10 \mathrm{HIV}+(5$ with NCI); 5 healthy, HIV seronegative (HIV-) controls matched by gender (100\% men), age (mean, 42.2) and education (mean 12.5). All HIV+ were receiving cART and virologically suppressed. Participants underwent lumbar puncture, phlebotomy and detailed medical, neurological and neurocognitive examinations. Neurosteroids were extracted from cerebrospinal fluid (CSF) and plasma and quantitated by enzyme Immunoassay (EIA). RESULTS: Levels of ADIOL in CSF were on average 6-fold higher than in plasma. Compared to HIV-individuals (CSF, 1289.7 \pm 374.6 ; plasma, $215.4 \pm 263.1$ ) and to HIV+ unimpaired subjects (CSF, 1010.7 \pm 450.3; plasma, $38.9 \pm 44.3)$ CSF ADIOL was decreased in impaired HIV+ subjects both in CSF $(507.2 \pm 188.1, \mathrm{p}<0.01)$ and plasma $(5.9 \pm 4.3)$. CONCLUSIONS: CSF $\Delta 5$-ADIOL levels were reduced in HIV + NCI participants. Since the expression of HSD17B14 is down-regulated by inflammation and up-regulated by the anti-inflammatory cytokine interleukin, (IL)-10, $\Delta 5$-ADIOL levels in CSF might be used as a biomarker for neuroinflammation in HIV. If confirmed, these results open the possibility of preclinical and clinical studies on exogenous ER beta ligands as potential interventions for HIV NCI. Study Supported By: California NeuroAIDS Tissue Network (CNTN): NIMH U01 MH083506; HIV Neurobehavioral Research Center P30 MH62512.

Disclosures: Dr. Saijo has nothing to disclose. Dr. Moore has nothing to disclose. Dr. Gouaux has nothing to disclose. Dr. Grant has received personal compensation for activities with Abbott Pharmaceuticals as a consultant. Dr. Ellis has received personal compensation for activities with Abbott and Neurogesx, Inc. as a speaker and consultant. Dr. Ellis holds stock in Abbott Laboratories Equity and Johnson and Johnson Equity.

\section{The role of stabilized neuropeptides derived from hyperimmune caprine sera (HICS) in motor neuron disease - implications for a novel therapeutic}

strategy Syed Haq, MBBS, BSc, PhD, DIC; Toni Ahtoniemi, PhD; Juho Oksman, MSc; Kimmo Lehtimäki, MSc; Marc Cerrada-Gimenez, PhD; Athene Westlake, MD; Chris Moore, MD, PhD, FRCP; Masud Haq, MD, FRCP; Nina Vartiainen, PhD; Deirdre McIntosh, PhD 
OBJECTIVE: To determine if targeting the HPA axis at a specific site using novel stabilized neuropeptides could elicit efficacy in the G93A SOD1 murine model and in patients from a multi-center open-label prospective ALS study conducted up to 12 months in duration. BACKGROUND: HICS has been demonstrated recently to have neuroprotective and neuroregenerative properties in several CNS in-vivo animal models and in a human phase II double-blind placebo cross-over clinical trial in secondary progressive multiple sclerosis. DESIGNS/METHODS: A. Age-matched G93A male/female mice $\mathrm{n}=20$ per treatment group (naïve/WT, naïve/SOD1 and HICS/SOD1) animals were treated daily $(100 \mathrm{mcg}$ s.c.) from day 60 to 150 and analyzed using standard methods of assessment including $1 \mathrm{H}$-MRS. B. A single-arm multi-center open-label study up to 12 months was conducted in 21 subjects with definite ALS receiving a daily s.c. dose of $1 \mathrm{ml}(4.5 \mathrm{mg} / \mathrm{ml})$ of HICS. The primary intention-to treat analyses were ALSFRS-R and survival. Secondary outcomes were ALSAQ-40, Jablecki score, FVC, muscle strength, BMI, safety and tolerability. RESULTS A. Significant maintenance was observed in rotarod latency, grip strength and concomitant changes observed in several key cellular metabolites using $1 \mathrm{H}-\mathrm{MRS}$ at 90 and 110 days. Delayed onset of disease and prolonged survival were also observed though not significant. B. In summary, no fall in the ALSRFS-R was noted in patients, with the majority having been treated for $>6$ months. patients showed a significant improvement in ALSFRS-R $(7.8 \%$, $\mathrm{p}<0.05)$, ALSAQ-40 $(15 \%, \mathrm{p}<0.05)$, a significant improvement in ALS scores of Jablecki $(11.4 \%, \mathrm{p}<0.05)$, muscle power and lung function during the study period were also noted. No adverse events were recorded during the entire duration of the study using HICS CONCLUSIONS: HICS showed efficacy in the G93A SOD1 mouse and in humans with ALS with no adverse event recorded. The latter confirmed the safety profile of the drug in two separate phase II clinical trials recently completed.

Study Supported By: Daval International Ltd.

Disclosures: Dr. Haq has received personal compensation for activities with Daval International Ltd. Dr. Ahtoniemi has nothing to disclose. Dr. Oksman has nothing to disclose. Dr. Lehtimäki has nothin to disclose. Dr. Cerrada-Gimenenz has nothing to disclose. Dr. Westlake's husband holds stock and/or stock options in Daval International Ltd. Dr. Moore has received personal compensation for activities with Daval International Ltd. Dr. Haq has received personal compensation for activities with Daval International Ltd. International Ltd. Dr. Haq has received personal compensation for activities with Daval International Ltd.
Dr. Vartiainen has nothing to disclose. Dr. McIntosh has received personal compensation for activities with Dr. Vartiainen has nothing
Daval International Ltd.

\section{${ }^{1} H$ MRS Reveals Decreased Motor Cortex Glutathione in Patients with ALS Nora Weiduschat; Xiangling Mao; Jonathan Hupf;} Nicole Armstrong; Dale Lange, MD, FAAN; Hiroshi Mitsumoto, MD, FAAN Dikoma Shungu, PhD

OBJECTIVE: To compare in vivo levels of glutathione (GSH) as measured by magnetic resonance spectroscopy (MRS) in the motor cortex of ALS patients with those in healthy volunteers (HV). BACKGROUND: Oxidative stress has been implicated in both sporadic and familial forms of amyotrophic lateral sclerosis (ALS). While glutathione levels have been associated with survival and cell pathology in preclinical ALS models, direct in vivo evidence of GSH deficiency in patients' brain is lacking. DESIGNS/METHODS: This cross-sectional observational study enrolled 12 ALS patients, diagnosed according to El Escorial criteria, and 11 age-matched HV. In vivo brain GSH spectra were recorded from a single $20 \times 25 \times 25 \mathrm{~mm}^{3}$ precentral gyrus voxel in the clinically most affected hemisphere on a 3.0 T GE MR system, using the standard J-edited spin echo difference method and an 8-channel phased-array head coil as described previously (Shungu 2012). GSH peak areas were derived by frequencydomain spectral fitting and expressed as ratios relative to the area of simultaneously acquired unsuppressed voxel tissue water (W). N-acetylaspartate (NAA), lactate, GABA and glutamate were obtained from the same voxel. RESULTS: Motor cortex GSH/W was decreased in the ALS group (Mean $=0.0013$, SD 0.0004) compared to HV (Mean $=0.0016$, SD 0.0004) $(\mathrm{p}=.021)$. Also NAA/Cr was decreased $(\mathrm{p}=.013)$ in ALS patients (Mean=2.03, SD 0.17) compared to HV (Mean=2.24, SD 0.19). There were no significant differences between the groups for any other metabolite or age. Age had no significant effect on GSH/W or NAA/Cr in our sample. CONCLUSIONS: To our knowledge, this is the first study to show decreased cortical GSH in vivo in ALS, directly implicating oxidative stress. Our finding of decreased $\mathrm{NAA} / \mathrm{Cr}$ in ALS is consistent with prior MRS studies and suggests neurodegeneration. Further studies are warranted to investigate MRS measurement of GSH as potential noninvasive biomarker for diagnosis and therapy monitoring. Shungu et al. NMR Biomed. 2012 Sep;25(9):1073-87.

Study Supported By: N/A

Disclosures: Dr. Weiduschat has nothing to disclose. Dr. Mao has nothing to disclose. Dr. Hupf has nothing to disclose. Dr. Armstrong has nothing to disclose. Dr. Lange has received personal compensatio for activities with Genzyme. Dr Lange has received research support from CSL Behring, GlaxoSmithKline, Cytokinetics, CSL Behring, Muscular Dystrophy Association and National Institutues of Health. Dr. Mitsumoto has received personal compensation for activities with Cytokinetics, Shinogi Pharma, and Biogen Idec. Dr. Shungu has nothing to disclose.

\section{Evidence of primary vascular injury after acute head trauma in the Traumatic Head Injury Neuroimaging Classification (THINC) Study Gunjan Parikh, MD; Abhik Ray-} Chaudhury, MD; Lawrence Latour

OBJECTIVE: To identify the neuroimaging correlates of these two pathological entities in hyperacute mild traumatic brain injury (mTBI). BACKGROUND: Pathological studies following severe head trauma reveal small hemorrhagic lesions of two types: punctate lesions within the corpus callosum, grey-white junction, or brainstem are associated with diffuse axonal injury (DAI) while "streak-like" lesions in the parasagittal white matter track penetrating vasculature. DESIGN/METHODS: This is a prospective study of acute TBI in the ED with evidence of blood on a clinical CT or research MRI. Focal lesions on T2* MRI were classified as i) microbleeds (punctate) or ii) linear lesions (tube-shaped, branching, multiple axial slices) and were graded for severity. Lesions were classified according to location, ischemia on DWI, edema on FLAIR, and focal findings on 3DT1. Concordance and discordance on CT was noted. Fisher exact was used. RESULTS: Of 256 studied over 24 months, 104
(41\%) had imaging evidence of hemorrhage, with $78 \%$ male, median age was $50,91 \%$ had arrival GCS $13-15,67 \%$ reported loss of consciousness, $65 \%$ reported amnesia, and 39\% had a negative CT. Median time injury to MRI was 17 hours. Of the 104, $21(20 \%)$ had microbleeds while 34 (33\%) had linear lesions. Microbleeds were distributed throughout the brain (lobar $=37$; deep $=3$; infratentorial $=9$ ), whereas linear lesions were found primarily in the anterior corona radiata $(n=28 ; 82 \%) .20(59 \%)$ linear lesions traversed white matter, gray matter, and sulcus on 3DT1. $23(68 \%)$ were graded as "severe". Ischemia on DWI or edema on FLAIR was association with linear lesions, $p=0.001$. CONCLUSIONS: Linear hemorrhagic lesions following $\mathrm{mTBI}$ are distinct from punctate microbleeds and may be the imaging correlate of vascular injury seen in histopathology following severe TBI. While these lesions are often equated to DAI, the MRI findings are suggestive of primary injury to the vasculature, and thus may be a target for acute therapy.

Study Supported By: NIH NINDS CNRM (Center for Neuroscience and Regenerative Medicine).

Disclosures: Dr. Parikh has nothing to disclose. Dr. Chaudhury has nothing to disclose. Dr. Latour has nothing to disclose.

\section{Natalizumab-associated progressive multifocal leukoencephalopathy (PML) in multiple sclerosis patients: Survival and functional outcome when} asymptomatic at diagnosis Tuan Dong-Si, MD; Sandra Richman, MD; Gary Bloomgren, MD, MBA; Madé Wenten; Jeffrey Philip; Shoibal Datta; James McIninch; Carmen Bozic, MD; Barry Ticho, MD, PhD; Nancy Richert, MD, PhD OBJECTIVE: To evaluate outcomes in natalizumab-treated multiple sclerosis (MS) patients who were asymptomatic when diagnosed with PML. BACKGROUND: As of January 1, 2013, 319 natalizumab-associated PML cases were confirmed in MS patients. DESIGNS/METHODS: Asymptomatic patients, diagnosed by MRI findings consistent with PML and JCV DNA positive CSF, were compared with patients symptomatic for PML at diagnosis. Demographics, MRI, and survival were analyzed. Expanded Disability Status Scale (EDSS) and Karnofsky Performance Scale (KPS) scores were recorded pre-PML, at diagnosis, and at 6 and 12 months post-PML diagnosis. Data are as of January 1, 2013. RESULTS: At diagnosis, 21 PML patients (mean age 45.1 years; $66.7 \%$ female; median natalizumab exposure 36 doses) were asymptomatic (AP); 298 (mean age 45.8 years; $70.5 \%$ female; median natalizumab exposure 38 doses) were symptomatic (SP). PML lesions on MRI in AP vs SP were $76 \%$ vs $36 \%$ unilobar, $14 \%$ vs $25 \%$ multilobar, and $10 \%$ vs $39 \%$ widespread, respectively. In both AP and SP, frontal lesions predominated. Symptoms developed in 10/21 AP at 13.8 weeks (mean) after diagnosis of PML; 5 of these patients had cognitive deficits and/or behavioral changes. Mean EDSS and KPS scores for AP vs SP, respectively, were as follows: pre-PML, EDSS $3.2(\mathrm{n}=14)$ vs $3.8(\mathrm{n}=145 ; P=0.263)$, KPS $88.0(\mathrm{n}=5)$ vs $80.1(\mathrm{n}=72 ; P=0.144)$; at diagnosis, EDSS $3.6(\mathrm{n}=8)$ vs $5.3(\mathrm{n}=154 ; P=0.020)$, KPS 66.7 $(\mathrm{n}=6)$ vs $53.6(\mathrm{n}=88 ; P=0.129) ;$ at 6 months, EDSS $4.7(\mathrm{n}=9)$ vs $6.9(\mathrm{n}=70 ; P=0.003)$, KPS $71.7(\mathrm{n}=9)$ vs $46.0(\mathrm{n}=88 ; P<0.001)$; at 12 months, EDSS $3.7(\mathrm{n}=3)$ vs $6.5(\mathrm{n}=39$; $P=0.066)$, KPS $70.0(\mathrm{n}=4)$ vs $46.9(\mathrm{n}=50 ; P=0.021)$. As of January $1,2013,100 \%$ of AP and $76.5 \%$ of SP have survived. CONCLUSIONS: Preliminary data suggest that PML patients who are asymptomatic at diagnosis may have improved survival and less functional disability compared with PML patients who are diagnosed when symptomatic.

Study Supported By: Biogen Idec Inc. and Elan Pharmaceuticals, Inc.

Disclosures: Dr. Dong-Si has received personal compensation for activities with Biogen Idec. Dr. Richman has received personal compensation for activities with Biogen Idec as an employee. Dr. Bloomgren has received personal compensation for activities with Biogen Idec as an employee. Dr. Wenten has received personal compensation for activities with Biogen Idec as an employee. Dr. Philip has received personal compensation for activities with Biogen Idec as an employee. Dr. Datta has received personal compensation for activities with Biogen Idec as an employee. Dr. McIninch has received personal compensation for activities with Biogen Idec as an employee. Dr. Bozic has received personal compensation for activities with Biogen Idec as an employee. Dr. Ticho has received personal compensation for activities with Biogen Idec as an employee. Dr. Richert has received personal compensation for activities with Biogen Idec as an employee.

\section{Pilot study of monthly pulse adrenocorticotropic hormone (ACTH) or methylprednisolone as an add-on therapy to beta-interferons for long-term treatment of multiple sclerosis Regina Berkovich, $M D$, PhD; Lilyana Amezcua,} MD; Dawood Subhani, MBBS; Steven Cen, PhD

OBJECTIVE: This single-center, examiner-blinded pilot study evaluated the efficacy and safety of pulse adrenocorticotropic hormone (ACTH) treatment added to beta-interferon in breakthrough multiple sclerosis (MS) compared with pulse methylprednisolone (MP). BACKGROUND: ACTH may have immune-modulating mechanisms beyond steroidogenesis that are relevant to the MS disease course. Although ACTH gel is approved to treat MS relapses, its use as pulse therapy is less known. DESIGNS/METHODS: MS patients receiving ongoing beta-interferon treatment were eligible if they had Expanded Disability Status Scale (EDSS) scores of 3.0-6.5 and $\geq 1$ relapse or new T2 or Gadolinium-enhanced lesion within the previous year. Patients were randomly assigned to open?label ACTH (80 units IM once/ day x 3 consecutive days) or MP (1 gram IV x 1 dose) monthly for 12 months, with assessments every 3 months for 15 months. Outcomes included relapse rate (primary), EDSS, MS Functional Composite, and MS Quality of Life. RESULTS: The study included 23 patients (ACTH: $n=12$, mean \pm SD EDSS 4.6 \pm 1.5 ; MP: $n=11$, mean \pm SD EDSS $4.6 \pm 1.3$ ). Over 15 months, the cumulative number of relapses/patient was 0.08 ( $95 \% \mathrm{CI}: 0.01-0.54)$ with ACTH and 0.80 (95\% CI: 0.36-1.75) with MP (risk ratio [MP vs ACTH]: 9.56 [95\% CI: 1.23-74.6; $P=0.03])$. The cumulative number of psychiatric episodes/patient was greater with MP $(0.55$ [95\% CI: $0.12-2.6])$ than with ACTH ( 0 episodes; $P<0.0001)$. The urinary tract infection cumulative incidence rate with MP was $0.65 /$ patient and with ACTH was 0.16 patient $(P=0.25)$. Mixed effect modeling showed no difference between groups in trajectory slopes of EDSS over time, but significantly stronger $(P=0.03)$ improvement in Mental Health Inventory for ACTH (slope: $0.95 /$ month $[P=0.02]$ ) compared with MP (slope: $0.29 /$ month $[P=0.32])$. CONCLUSIONS: These data suggest a potential benefit of ACTH pulse therapy 
in breakthrough MS with more favorable relapse and psychiatric side effect profiles. Further studies, including randomized controlled trials are needed to validate these findings. Study Supported By: Questcor Pharmaceuticals, Inc.

Disclosures: Dr. Berkovich has received personal compensation for activities with Bayer, Biogen Idec, Genzyme, Teva, Questcor, Acorda, and Avanir. Dr. Berkovich has received research support from Questco Inc and Teva. Dr. Amezcua has received personal compensation for activities with Biogen, Novartis, Acorda Teva, Serono/Pfizer. Dr. Amezcua has received research support from Novartis and Acorda. Dr. Subhani has nothing to disclose. Dr. Cen has nothing to disclose.

\section{Percutaneous Transluminal Venous Angioplasty (PTVA) is Ineffective in Correcting Chronic Cerebrospinal Venous Insufficiency (CCSVI) and May Increase Multiple Sclerosis(MS)Disease Activity in the Short Term: Safety and Efficacy Results of the 6-Month, Double-Blinded, Sham-Controlled, Prospective, Randomized Endovascular Therapy in MS (PREMiSe) trial Robert Zivadi-} nov, MD, PhD, FAAN; Adnan Siddiqui; Yuval Karmon; Yu Jihnhee; Karen Marn BA; Vesela Valnarov; Cheryl Kennedy; Murali Ramanathan, PhD; Deepa Ramasamy; Dolic Kresemir; David Hojnacki, MD; Ellen Carl, MS; Michael Dwyer, MD; Niels Bergsland, MS; Elad Levy; Hopkins Nelson; Bianca Guttman

OBJECTIVE: To investigate the safety and efficacy of percutaneous transluminal venous angioplasty (PTVA) for correcting chronic cerebrospinal venous insufficiency (CCSVI) in multiple sclerosis (MS). BACKGROUND: The safety and efficacy of PTVA for correcting CCSVI was not tested in randomized, double-blinded, sham-controlled studies. DESIGN/METHODS The trial was planned in two phases. Phase I was an open-label safety 6-month follow-up study that included 10 MS patients, whereas phase II, initiated after completion of phase I, was a randomized, double-blinded, sham-controlled PTVA intervention, 6-month follow-up study that included 19 patients ( 10 in the sham and 9 in the treated arm). Qualification on noninvasive ( $\geq 2$ Doppler sonography criteria) and invasive ( $\geq 50 \%$ lumen reduction on catheter venography in the azygous or internal jugular veins) screening assessments was needed for study participation. All patients were assessed at 1,3 and 6 months post-PTVA with MRI, clinical and Doppler sonography. The primary endpoints were safety at 24 hours and 1 month, venous outflow restoration ( $>75 \%$ compared to baseline), and the effect of PTVA on new lesion activity and relapse rate over 6 months. Secondary endpoints included changes in disability and MR brain volume. Neuropsychological and quality of life outcomes were considered tertiary endpoints. RESULTS: No intra- or post-operative complications occurred during the study. Venous outflow restoration of $>75 \%$ compared to baseline, was achieved only in phase I at 1 month, but not in phase II. In phase II, higher MRI [cumulative number of new contrast enhancing (19 vs. $3, \mathrm{p}=0.062)$ and new T2 lesions ( $17 \mathrm{vs.} 3, \mathrm{p}=0.066)]$ and relapse activity ( $4 \mathrm{vs.} 1, \mathrm{p}=0.389)$ were identified in the treated vs. the sham arm over 6 months. No differences in secondary or tertiary endpoints between phase II groups were detected. CONCLUSIONS: PTVA was ineffective in correcting CCSVI and may increase MS disease activity in the short-term.

Study Supported By: The authors declare that their study was funded with internal resources of the Buffalo Neuroimaging Analysis Center, Jacobs MS Comprehensive and Research Center, University at Buffalo. In addition, they received support from the Direct MS Foundation, Kaleida-Health, Volcano, ev3, Codman, the Jacquemin Foundation, and from minor donors.

Disclosures: Dr. Zivadinov has received personal compensation for activities with Teva Neurosciences, Biogen Idec, Questcor, Genzyme-Sanofi, Novartis, Bracco, Bayer and EMD Serono. Dr. Zivadinov has received research support from the National Multiple Sclerosis Society, Department of Defense, Biogen Idec, Teva Neuroscience, Teva Pharmaceuticals, EMD Serono, Genzyme-Sanofi, Questcor, Bracco, Novartis, and Greatbatch. Dr. Siddiqui has received personal compensation for activities with Codman \& Shurtleff, Inc., Concentric Medical, ev3/Covidien Vascular Therapies, Penumbra and Micrus Endovascular, GuidePoin Global Consulting, Genentech, Abbott Vascular, American Association of Neurological Surgeons, Neocure Group LLC and Stryker Neurovascular. Dr. Siddiqui has received compensation for serving on the board of Valor Medical, Intratech Medical, Hotspur and StimSox. Dr. Siddiqui holds stock and/or stock options in Hotspur, Intratech Medical, Valor Medical. Dr. Siddiqui has received research support from the National Institutes of Health. Dr. Benedict has received personal compensation for activities with Actelion, Biogen Idec, Bayer and Novartis. Dr. Benedict has received royalty payments from Psychological Assessmen Resources. Dr. Benedict has received research support from Acorda, Biogen Idec, and Shire. Dr. Karmon has nothing to disclose. Dr. Jihnhee has nothing to disclose. Dr. Marr has nothing to disclose. Dr. Valnarov has nothing to disclose. Dr. Kennedy has nothing to disclose. Dr. Ramanathan has received personal compensation for activities with EMD Serono, Biogen Idec, Allergan, Netezza, Pfizer, Novartis, the National pensation for activities with EMD Serono, Biogen Idec, Allergan, Netezza, Pfizer, Novartis, the Nationa
Multiple Sclerosis Society, the Department of Defense, Jog for the Jake Foundation, the National Institutes Multiple Sclerosis Society, the Department of Defense, Jog for the Jake Foundation, the National Institutes
of Health, and National Science Foundation. Dr. Ramanathan has received compensation in an editoria capacity for the American Association of Pharmaceutical Scientists. Dr. Ramanathan received research support from EMD Serono, Biogen Idec, Allergan, Netezza, Pfizer, Novartis, the National Multiple Sclerosis Society, the Department of Defense, Jog for the Jake Foundation, the National Institutes of Health. Dr. Ramasamy has nothing to disclose. Dr. Kresimir has nothing to disclose. Dr. Hojnacki has received personal compensation for activities with Biogen Idec, EMD Serono, Pfizer, Teva, and Genzyme. Dr. Carl has nothing to disclose. Dr. Dwyer has nothing to disclose. Dr. Bergsland has nothing to disclose. Dr. Levy has received personal compensation for activities with Cordis Neurovascular, Micrus Endovascular, Abbott Vascular, ev3 Vascula Therapies, TheraSyn Sensors, Inc., Boston Scientific, Codman \& Shurtleff, Inc. Dr. Levy holds stock and/o stock options in Micrus Endovascular, Intratech Medical Ltd., and Mynx/Access Closure. Dr. Levy has received research support from Micrus Endovascular and ev3/Covidien. Dr. Hopkins has received personal compensation for activities with Abbott, Boston Scientific, Cordis, Micrus, W. L. Gore; AccessClosure, Augmenix, Valor Medical, Claret Medical Inc, Cleveland Clinic, Complete Conference Management, Cordis, SCAI, University of Southern California, and VIVA Physicians. Dr. Hopkins has received research support from St. Jude Medical and Toshiba. Dr. Weinstock-Guttman has received personal compensation for activities with Biogen Idec, Teva Neurosciences, EMD Serono, Pfizer, Novartis, Genzyme, and Acorda. Dr. Weinstock-Guttman has received research support from Biogen Idec, Teva Neurosciences, EMD Serono, Pfizer, Novartis, Acorda, ITN, Questcor Shire, NMSS, NIH and Aspreva. 


\section{Neurology}

2013 Emerging Science Abstracts

Neurology 2013;80;e201-e206

DOI 10.1212/WNL.0b013e3182924c84

This information is current as of May 6, 2013

Updated Information \& Services

Permissions \& Licensing

Reprints including high resolution figures, can be found at: http://n.neurology.org/content/80/19/e201.full

Information about reproducing this article in parts (figures,tables) or in its entirety can be found online at:

http://www.neurology.org/about/about_the_journal\#permissions

Information about ordering reprints can be found online:

http://n.neurology.org/subscribers/advertise

Neurology ${ }^{\circledR}$ is the official journal of the American Academy of Neurology. Published continuously since 1951, it is now a weekly with 48 issues per year. Copyright @ 2013 American Academy of Neurology. All rights reserved. Print ISSN: 0028-3878. Online ISSN: 1526-632X.

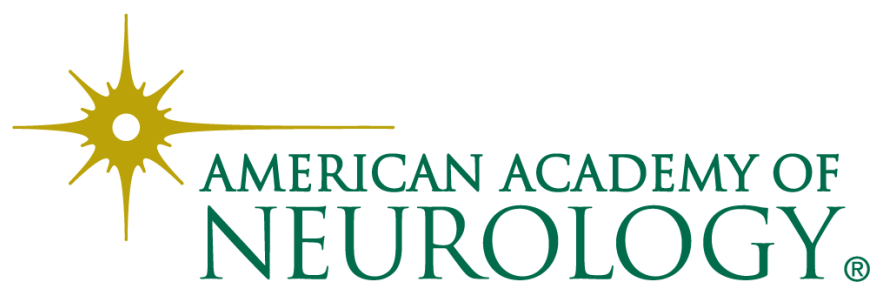

